International Journal of Enginering \& Technology, $7(4.35)(2018) 342-346$
WPC

\title{
Analysis by Means of Surface Response to Chemical Composition and Pozzolanic Reactivity of Ultrafine Treated Rice Husk Ash (UFTRHA) as Cementing Additive Material
}

\author{
Siti Asmahani Saad ${ }^{1 *}$, Nasir Shafiq ${ }^{2}$, Maisarah $\mathrm{Ali}^{3}$, Mariana Mohamed Osman ${ }^{4}$ \\ ${ }^{1,3}$ Kulliyyah of Engineering, International Islamic University Malaysia, Malaysia \\ ${ }^{2}$ Faculty of Engineering, University of Technology PETRONAS, Malaysia \\ ${ }^{4}$ Kulliyyah of Architecture and Environmental Design, International Islamic University Malaysia, Malaysia \\ *Corresponding author E-mail: asmahanisaad@iium.edu.my
}

\begin{abstract}
Pozzolanic reactive material is considered as one of the most essential characteristic of cementing additive material in concrete technology application. Normally, the reactive material contains abundant silica that enhances concrete strength activity. Undeniably, it is proven that rice husk ash (RHA) possesses large quantity of silica that induces the pozzolanic reaction in concrete. Nevertheless, usage of conventional RHA is still widely accepted in concrete industry nowadays. One of the setback of conventional RHA incorporation is simply because of its properties inconsistency. Therefore, enhancement on the RHA properties by introduction of a specific pretreatment prior to incineration process is expected to provide an alternative way in order to produce highly reactive cementing additive material from locally available agricultural by-product, the rice husk. In this paper, a total number of 30 experimental set points was conducted. Statistical analysis was conducted for four independent variables and two responses using Response Surface Method (RSM). The analysis was completed using a commercial software set (Design-Expert) for experimental design and analysis. The independent variables were $\mathrm{HCl}$ concentration, soaking time, burning temperature and soaking temperature. Meanwhile, the responses investigated in this study were including cumulative pozzolan percentage and electric conductivity decrement from 0 to 2 minutes. As for the statistical analysis of the data for response 1 , the cumulative pozzolan percentage calculated from the model was in-line with the experimental data, with Rsquared value of 0.9565 . Hence, the result validates the precision of the model. On the other hand, the R-squared value for response 2 which is the EC decrement from 0 - 2 Minutes, it shows that the model was in agreement to the experimental values at 0.9342 . Thus, it is again justifies the model accuracy.
\end{abstract}

Keywords: Ultrafine Treated Rice Husk Ash (UFTRHA); Cementing Additive Material; Response Surface Method (RSM): high energy milling.

\section{Introduction}

In 2016, world paddy production was documented to have more than 740 million tons [1]. Husk covers approximately $20 \%$ out of the total mass of the paddy plant from this massive production [2]. Eventually, the generated rice husk was over 160 million tons last year. According to BERNAS, which is a body responsible in domestic paddy and rice industry in Malaysia, this abundance byproduct is usually used as a biomass fuel of boiler for electricity generation within the factory area. However, the rice husk generated is still underutilized at the factory. The problem becomes complicated when BERNAS has to move out the rice husk from the factory since this activity incurred extra cost to the company. Therefore, there is an urge to make use of this abundance byproduct in the industries namely construction industry.

Recently, an extensive research on incorporation of rice husk ash (RHA) in concrete has been done attributable to high in silica content. Despite of high number of experimental works done in this area since 1970s, quality of the conventional rice husk ash studied is still compromised. Unlike other type of material such as pulverized fuel ash and silica fume, this material is still not widely used as additive material among the construction key players, although the research of rice husk ash has begun in 1970s. Among the rea- sons that hindered the utilization of RHA as SCM in current construction industry are due to inconsistency of its amorphousness degree with undesirable composition i.e. potassium oxide $\left(\mathrm{K}_{2} \mathrm{O}\right)$ and sodium oxide $\left(\mathrm{Na}_{2} \mathrm{O}\right)$. These compositions cause pure silica content in the rice husk ash to melt at low temperature i.e. less than $800^{\circ} \mathrm{C}$ [3]. This particular reaction is known as eutectic reaction. When the eutectic reaction occur, it will form crystalline silica and impart black colour of the produced RHA as well. That is a huge reason why the rice husk is also very sensitive towards temperature during burning stage. The sensitivity towards burning condition causes inconsistency of the properties of rice husk ash produced. Hence, it is regarded as the main reason that lack of usage of this material as additive material in current construction sector. Generally, this phenomenon occurs due to the metallic impurities that encapsulate on the surface of the husk. These metallic impurities induces surface melting during the burning process and causing reduction of specific surface area of the burnt ash. Consequently, the pozzolanic behavior of the ashes reduces as well [4]. In order to produce high content of silica in rice husk ash, removal of impurities on the rice husk surface prior to completion of incineration process is highly essential. Several researches reported that the impurities can be greatly eliminated via acid-leaching treatment. [5], [6] Production of a high quality reactive amorphous silica from this agricultural waste is essential in order to improve the properties 
of concrete at its best. Therefore, little addition of this excellent quality material is sufficient in order to achieve high quality concrete, hence cost and time effective.

In the existing researches, most of the activities concentrated on pretreatment of rice husk using acid leaching concentrated on physical and chemical properties such as chemical content percentage, degree of material amorphousness, degree of pozzolanic behavior etc. Basic engineering properties such as compressive strength has been studied as well [4], [6]-[8]. Despite of the fact, detail study on the mechanical properties as well as durability of concrete incorporating pretreated rice husk ash is still limited. In addition, past researches focused on the acid leaching pretreatment using high concentration inorganic acid i.e. nitric acid $\left(\mathrm{HNO}_{3}\right)$, hydrochloric acid $(\mathrm{HCl})$, and sulphuric acid $\left(\mathrm{H}_{2} \mathrm{SO}_{4}\right)$. Utilization of high acid concentrations i.e. $1 \mathrm{M}$ to $18 \mathrm{M}$, will lead towards cost escalation in terms of purchasing of raw material needed and treatment of the chemical wastes generated after completion of the pretreatment procedure. According to research reported by Sankar et al. (2015), usage of $10 \%$ hydrochloric acid $(\mathrm{HCl})$, which equivalent to $3.26 \mathrm{M}$ has improved the amorphousness degree of the treated rice husk ash yield [9]. Nevertheless, the study was limited to pretreatment method using a single acid concentration and incineration temperature

This research study is intended to explore the gaps in existing body of knowledge on simple thermochemical pretreatment method of raw rice husk via low concentration of acid namely Hydrochloric acid $(\mathrm{HCl})$ and calcination temperature for an excellent SCM production in concrete technology application. It was also aimed to extend the investigation of producing highly reactive pozzolana in ultrafine size, with particle diameter of less than $5 \mu \mathrm{m}$ through mechanical activation using planetary ball mill. To date, literature regarding to the usage of hydrochloric acid as a leaching medium in pretreatment process and the calcination temperature are quite substantial. However, relationship between different acid concentrations, pretreatment temperature, pretreatment duration and calcination temperatures have yet to be established. In light of mechanical activation process, most of studies have been done to test materials such as metakaolin and fly ash but study on the effect of mechanical activation via planetary ball mill to conventional rice husk ash or treated rice husk ash has never been done previously. Therefore, there is a significant to further extend the investigation on the effect of low concentration of acid to the quality and performance of the ultrafine treated rice husk ash (UFTRHA) as highly reactive cementing additive material as well as the effect of mechanical activation via planetary ball mill to the UFTRHA.

\section{Methodology}

\subsection{Pre-Treatment Method of Ultrafine Treated Rice Husk Ash (UFTRHA)}

In this research work, source of fresh rice husk was obtained in one of rice factory in Perak (BERNAS). Before burning process took place, the rice husk was treated using $0.01 \mathrm{M}, 0.06 \mathrm{M}$ and $0.1 \mathrm{M}$ hydrochloric acid $(\mathrm{HCl})$. The specimens were immersed and heated at various temperatures i.e. from $30^{\circ} \mathrm{C}$ to $80^{\circ} \mathrm{C}$ in the acid solution for 1 to 5 hours respectively. Next, the samples were cleaned using distilled water until it reached neutral $\mathrm{pH}$. The samples were then been dried in laboratory oven. It was then incinerated accordingly using Protherm Ashing furnace. It was completed at $600^{\circ} \mathrm{C}, 700^{\circ} \mathrm{C}$ and $800^{\circ} \mathrm{C}$ for 1 hour retention time in accordance to combination of experimental run suggested by RSM. The ultrafine treated rice husk ash (UFTRHA) was then milled in planetary ball mill at a duration of 15 minutes by adopting a value of 15:1 for ball-to-powder ratio (BPR).

\subsection{Chemical and Physical Characterisation of Ul- trafine Treated Rice Husk Ash (UFTRHA)}

In order to investigate chemical composition of UFTRHA, X-ray fluorescence (XRF) test has been conducted thoroughly. The test was done for UFTRHA sample that undergone pretreatment in $0.1 \mathrm{~N} \mathrm{HCl}$ solution at $80^{\circ} \mathrm{C}$. The analysis was done by using spectrometer of Bruker Axs S4 Pioneer. The test was in compliance with BS EN 12677. Meanwhile, as for its physical characterization part, particle size analysis (PSA) was successfully conducted using Scirocco 2000 Malvern instrument mastersizer.

\subsection{Pozzolanic Reactivity Test}

Pozzolanic reactivity test is ubiquitous in reactivity level investigation of any cementing additive material. In this regard, rapid evaluation examination procedure were conducted. This investigation method is referred as pozzolanic reactivity test by using direct measurement method. It was accomplished by recording electrical conductivity reduction assessment by utilizing a conductivity meter from 0 to 2 minutes time frame. In this experimental setup, $200 \mathrm{ml}$ of saturated calcium hydroxide solution $\left(\mathrm{Ca}(\mathrm{OH})_{2}\right)$ or portlandite were prepared at a specific temperature of $40^{\circ} \mathrm{C}$. After that, the electrical conductivity data need to be recorded prior to inclusion of $5 \mathrm{~g}$ of the powdered UFTRHA specimen into the saturated portlandite solution and after the inclusion as well at 0 and 2 minutes durations, respectively. Liquid-to-solid (1/s) ratio of the pozzolan in the liquid suspension considered was 40 as reported by other researchers as well [10]-[13].

\subsection{Analysis of Data Using Response Surface Method (RSM)}

Response surface method is known as one of a powerful tool in order to analyse the relationship between parameters and responses or the output of the research experimental framework. In addition, the generated model is useful to evaluate the effects of each desired parameters and their interaction on each of the response variables [14]. The RSM has several benefits, e.g. advantageous for model prediction for every response, beneficial in constructing a strong model with limited number of experimental data points, useful in assessing interaction effect between the factors as well as allowing the user to obtain the optimal response [15].

In this paper, central composite design (CCD) coupled with RSM analysis was conducted for four independent variables and two responses. The analysis was completed using a commercially available software package (Design-Expert) for experimental design and analysis. The independent variables were $\mathrm{HCl}$ concentration (A), soaking time (B), burning temperature $(\mathrm{C})$ and soaking temperature (D). These independent variables were named as $(-1,1)$ interval in which the minimum and maximum value levels were named as -1 and +1 , respectively Range of the selected process variables are presented in Table 1.

Table 1: Variables and boundary level for response surface method of analysis.

\begin{tabular}{|c|c|c|c|c|c|}
\hline Variables & Unit & \multirow{2}{*}{$\begin{array}{c}\text { Symbol } \\
\text { used }\end{array}$} & \multicolumn{3}{|c|}{ Boundary level } \\
\cline { 4 - 6 } & & $\mathrm{A}$ & 0.01 & 0.06 & 0.1 \\
\hline $\begin{array}{c}\mathrm{HCl} \text { Concen- } \\
\text { tration }\end{array}$ & $\begin{array}{c}\text { Molar } \\
(\mathrm{M})\end{array}$ & $\mathrm{B}$ & 1 & 3 & 5 \\
\hline Soaking time & Hour(s) & $\mathrm{B}$ & 600 & 700 & 800 \\
\hline $\begin{array}{c}\text { Burning } \\
\text { temperature }\end{array}$ & ${ }^{\circ} \mathrm{C}$ & $\mathrm{C}$ & 30 & 55 & 80 \\
\hline $\begin{array}{c}\text { Soaking } \\
\text { temperature }\end{array}$ & ${ }^{\circ} \mathrm{C}$ & $\mathrm{D}$ & & & \\
\hline
\end{tabular}




\section{Results and Discussion}

\subsection{Variable Array of Response Surface Method (RSM)}

In this study, a total number of 30 experimental set points or samples was conducted and prepared accordingly. Responses investigated in this study were including cumulative pozzolan percentage (Y1) and electric conductivity decrement from 0 to 2 minutes (Y2). Cumulative pozzolan percentage is define as total addition value of several components namely $\mathrm{SiO}_{2}, \mathrm{Fe}_{2} \mathrm{O}_{3}$ and $\mathrm{Al}_{2} \mathrm{O}_{3}$. According to ASTM C 618 (2015), the summation of these oxide components must be more than $70 \%$ in order to be classified as class $\mathrm{F}$ Pozzolan material group [16]. Table 2 tabulates the various experimental run combination according to RSM array together with the results for further analysis.

Table 2: Combination of experimental run based on RSM array.

\begin{tabular}{|c|c|c|c|c|c|c|}
\hline Run & $\begin{array}{c}\text { Factor } \\
1: \\
\mathrm{HCl} \\
\text { Conc. } \\
\text { (M) } \\
\text { (A) }\end{array}$ & $\begin{array}{c}\text { Factor } \\
2: \\
\text { Soa- } \\
\text { king } \\
\text { time } \\
\text { (B) }\end{array}$ & $\begin{array}{c}\text { Factor } \\
3: \\
\text { Burning } \\
\text { temperature } \\
\text { (C) }\end{array}$ & $\begin{array}{c}\text { Factor } \\
4: \\
\text { Soa- } \\
\text { king } \\
\text { Temp. } \\
\text { (D) }\end{array}$ & $\begin{array}{c}\text { Res- } \\
\text { ponse 1: } \\
\text { Cumu- } \\
\text { lative } \\
\text { pozzolan } \\
\text { Percen- } \\
\text { tage } \\
\text { (Y1) }\end{array}$ & $\begin{array}{l}\text { Res-ponse } \\
2: \\
\text { Electric } \\
\text { Conduc- } \\
\text { tivity } \\
\text { (EC) } \\
\text { decrement } \\
\text { from } 0 \text { - } 2 \\
\text { Minutes } \\
\text { (Y2) }\end{array}$ \\
\hline 1 & 0.1 & 3 & 700 & 55 & 94.67 & 5.94 \\
\hline 2 & 0.1 & 1 & 600 & 30 & 89.32 & 4.25 \\
\hline 3 & 0.01 & 5 & 800 & 80 & 98.39 & 6.87 \\
\hline 4 & 0.1 & 4 & 600 & 80 & 99.11 & 7.33 \\
\hline 5 & 0.06 & 3 & 700 & 55 & 95.81 & 6.13 \\
\hline 6 & 0.06 & 3 & 700 & 55 & 94.32 & 5.34 \\
\hline 7 & 0.01 & 5 & 800 & 30 & 90.8 & 4.43 \\
\hline 8 & 0.06 & 3 & 700 & 55 & 95.45 & 6.17 \\
\hline 9 & 0.01 & 5 & 600 & 80 & 98.65 & 6.93 \\
\hline 10 & 0.01 & 1 & 600 & 30 & 87.65 & 3.85 \\
\hline 11 & 0.1 & 1 & 800 & 30 & 90.97 & 4.52 \\
\hline 12 & 0.06 & 3 & 700 & 55 & 95.81 & 6.2 \\
\hline 13 & 0.06 & 3 & 700 & 30 & 92.55 & 5.01 \\
\hline 14 & 0.06 & 3 & 700 & 55 & 94.39 & 5.81 \\
\hline 15 & 0.1 & 5 & 800 & 80 & 98.32 & 6.65 \\
\hline 16 & 0.01 & 3 & 700 & 55 & 95.85 & 6.21 \\
\hline 17 & 0.06 & 3 & 600 & 55 & 97.35 & 6.41 \\
\hline 18 & 0.1 & 5 & 600 & 30 & 91.2 & 4.65 \\
\hline 19 & 0.01 & 1 & 800 & 30 & 86.27 & 3.54 \\
\hline 20 & 0.06 & 3 & 700 & 80 & 99.01 & 7.06 \\
\hline 21 & 0.06 & 1 & 700 & 55 & 93.66 & 5.21 \\
\hline 22 & 0.1 & 5 & 600 & 80 & 98 & 6.71 \\
\hline 23 & 0.01 & 1 & 600 & 80 & 93.61 & 5.22 \\
\hline 24 & 0.06 & 5 & 700 & 55 & 97.92 & 6.54 \\
\hline 25 & 0.01 & 5 & 600 & 30 & 91.75 & 4.87 \\
\hline 26 & 0.06 & 3 & 700 & 55 & 95.81 & 6.13 \\
\hline 27 & 0.1 & 1 & 800 & 80 & 98.28 & 6.75 \\
\hline 28 & 0.1 & 5 & 800 & 30 & 91.25 & 4.77 \\
\hline 29 & 0.01 & 1 & 800 & 80 & 94.71 & 5.92 \\
\hline 30 & 0.06 & 3 & 800 & 55 & 95.68 & 6.17 \\
\hline
\end{tabular}

As for the first response, experimental results was deduced from XRF analysis. It can be observed that the cumulative pozzolan percentage of all 30 experimental set points were recorded to be more than $70 \%$. In addition, the predominant content was silica $\left(\mathrm{SiO}_{2}\right)$. It was also noted that, the cumulative pozzolan percentage for UFTRHA pretreated using $0.1 \mathrm{M} \mathrm{HCl}$ at $80^{\circ} \mathrm{C}$ for four hours and incinerated at $600^{\circ} \mathrm{C}$ has greatest content among other samples that were produced at $700^{\circ} \mathrm{C}$ and $800^{\circ} \mathrm{C}$.

In order to complete the RSM array, pozzolanic evaluation analysis of the UFTRHA samples were done by measuring electrical conductivity (EC) value at zero and two minutes, respectively. The decrement amount of the EC readings from zero to two minutes were noted as the second response in this study. Based on the findings, the largest value of electric conductivity difference was recorded for the fourth experimental run in the RSM array (i.e. $7.33 \mathrm{mS} / \mathrm{cm}$ ). Previously, the same tested UFTRHA sample had the highest cumulative pozzolan percentage. Therefore, it can be said that high amount of pozzolanic components increases pozzolanic reactivity of a material.

In addition, particle size of the material plays an important role in reactivity level of a material as well. In this regard, vigorous grinding process via high speed grinding using planetary ball mill reduces the particle size of material tremendously. The process induced superior velocity of the ball movements in the milling container. During the grinding process, grinding media (balls) and feed stock (UFTRHA) experienced a vigorous shearing condition and thus the finer particle size produced in the end of the process. Referring to the data tabulated in Table 3, UFTRHA that had been treated for four hours and burned at $600^{\circ} \mathrm{C}$ had smallest particle size than that of the other UFTRHA specimens with $\mathrm{d}(0.1), \mathrm{d}(0.5)$ and $\mathrm{d}(0.9)$ of $1.416 \mu \mathrm{m}, 4.364 \mu \mathrm{m}$ and $14.043 \mu \mathrm{m}$, subsequently.

Table 3: Particle size analysis of UFTRHA at various burning temperature at 4 hours of immersion period.

\begin{tabular}{|c|c|c|c|c|}
\hline \multirow{2}{*}{$\begin{array}{l}\text { Pretreatment } \\
\text { Soaking Dura- } \\
\text { tion (Hrs) }\end{array}$} & $\begin{array}{l}\text { Incineration } \\
\text { Temp. }\left({ }^{\circ} \mathbf{C}\right)\end{array}$ & \multicolumn{3}{|c|}{ Particle Size $(\boldsymbol{\mu m})$} \\
\cline { 3 - 5 } & & $d(0.1)$ & $d(0.5)$ & $d(0.9)$ \\
\hline \multirow{3}{*}{4} & $600^{\circ} \mathrm{C}$ & 1.416 & 4.364 & 14.043 \\
\cline { 2 - 5 } & $700^{\circ} \mathrm{C}$ & 1.460 & 4.676 & 14.768 \\
\cline { 2 - 5 } & $800^{\circ} \mathrm{C}$ & 1.205 & 4.948 & 21.638 \\
\hline
\end{tabular}

\subsection{Statistical Data Analysis}

According to Table 4, for the first response, soaking temperature (D) demonstrated the highest $\mathrm{F}$ value of 215.32 , followed by $\mathrm{HCl}$ concentration together with soaking time effect $(\mathrm{AB})$ and the quadratic effect soaking temperature $\left(\mathrm{D}^{2}\right)$ with the $\mathrm{F}$ value of 9.6 and 4.18, respectively in analysis of Variance (ANOVA). In addition, cumulative pozzolan percentage projected from the model was conforming to the experimental data, with R-squared value of 0.9565 . Therefore, it justifies the model precision.

On the other hand, Table 5 tabulates the analysis of variance (ANOVA) for second response. Based on the analysis, it is noted that immersion temperature (D) recorded to have the highest $\mathrm{F}$ value of 227.93. It was then followed by immersion time effect $(\mathrm{AB})$ with a value of 27.04 and the quadratic effect immersion time $\left(\mathrm{B}^{2}\right)$ with the $\mathrm{F}$ value of 9.46 . Meanwhile, the $\mathrm{R}$-squared value for EC decrement from 0 - 2 Minutes from the model was inline with the experimental values at 0.9342 . Therefore, it confirms the model accurateness. In addition, the tested factor or parameters in this experimental works can be applied with other additive materials that needed to be treated as well.

Table 4: Analysis of variance (ANOVA) for models evaluation for first response.

\begin{tabular}{|c|c|c|c|c|c|c|}
\hline Responses & Source & $\begin{array}{l}\text { Sum of } \\
\text { Square } \\
\text { s }\end{array}$ & $\begin{array}{l}\text { Degree } \\
\text { of } \\
\text { Free- } \\
\text { dom }\end{array}$ & $\begin{array}{l}\text { Mean } \\
\text { Squar } \\
\text { e }\end{array}$ & $\begin{array}{l}\text { F } \\
\text { Value }\end{array}$ & $\begin{array}{l}\text { p-value } \\
\text { Prob> } \\
\text { F }\end{array}$ \\
\hline \multirow[t]{10}{*}{$\begin{array}{l}\text { Cumula- } \\
\text { tive } \\
\text { Pozzolan } \\
\text { Percent- } \\
\text { age }\end{array}$} & Model & 331.09 & 14 & 23.65 & 23.54 & $\begin{array}{l}< \\
0.0001 \\
\mathrm{a}\end{array}$ \\
\hline & $\mathrm{A}$ & 7.05 & 1 & 7.05 & 7.02 & 0.0182 \\
\hline & B & 30.34 & 1 & 30.34 & 30.2 & $\begin{array}{l}< \\
0.0001\end{array}$ \\
\hline & $\mathrm{C}$ & $\begin{array}{l}3.79 \mathrm{E}- \\
05\end{array}$ & 1 & $\begin{array}{l}3.79 \mathrm{E} \\
-05\end{array}$ & $\begin{array}{l}3.77 \mathrm{E} \\
-05\end{array}$ & 0.9952 \\
\hline & $\mathrm{D}$ & 216.28 & 1 & $\begin{array}{l}216.2 \\
8\end{array}$ & $\begin{array}{l}215.3 \\
2\end{array}$ & $\begin{array}{l}< \\
0.0001\end{array}$ \\
\hline & $\mathrm{AB}$ & 9.64 & 1 & 9.64 & 9.6 & 0.0073 \\
\hline & $\mathrm{AC}$ & 1.26 & 1 & 1.26 & 1.25 & 0.2809 \\
\hline & $\mathrm{AD}$ & 0.04 & 1 & 0.04 & 0.039 & 0.8452 \\
\hline & $\mathrm{BC}$ & 0.95 & 1 & 0.95 & 0.95 & 0.3459 \\
\hline & $\mathrm{BD}$ & 0.014 & 1 & 0.014 & 0.014 & 0.9066 \\
\hline
\end{tabular}




\begin{tabular}{|l|l|l|l|l|l|l|}
\hline & CD & 0.55 & 1 & 0.55 & 0.54 & 0.4718 \\
\hline & A2 & 3.43 & 1 & 3.43 & 3.42 & 0.0843 \\
\hline & B2 & 1.86 & 1 & 1.86 & 1.85 & 0.1938 \\
\hline & C2 & 0.087 & 1 & 0.087 & 0.087 & 0.7723 \\
\hline & D2 & 4.2 & 1 & 4.2 & 4.18 & 0.0588 \\
\hline & $\begin{array}{l}\text { Lack of } \\
\text { Fit }\end{array}$ & 12.48 & 10 & 1.25 & 2.42 & $\begin{array}{l}0.1712 \\
\mathrm{~b}\end{array}$ \\
\hline & $\begin{array}{l}\text { R- } \\
\text { Squared }\end{array}$ & 0.9565 & & & & \\
\hline & $\begin{array}{l}\text { Adjust- } \\
\text { ed R- } \\
\text { squared }\end{array}$ & 0.9158 & & & & \\
\hline
\end{tabular}

\section{Conclusion}

Utilising local agricultural waste as SCM is seen as one of the best solution in order to maximise the usage of the by product. Based on the results, it shows that, the optimum conditions in pretreatment process possesses a significant role in terms of improving the chemical composition of UFTRHA as highly reactive cementing additive material. Meanwhile, high speed grinding procedure ensure the smallest particle size of produced UFTRHA that resulted in high pozzolanic reactivity level. These properties are important so that highly reactive additive material can be generated for a better concrete technology practice. In light of the chemical composition analysis, the cumulative pozzolan percentage for UFTRHA pretreated using $0.1 \mathrm{M} \mathrm{HCl}$ at $80^{\circ} \mathrm{C}$ for four hours and incinerated at $600^{\circ} \mathrm{C}$ has highest percentage amount of $99.11 \%$. The similar sample also recorded largest value of EC decrement and hence verify its pozzolanicity level at $7.33 \mathrm{mS} / \mathrm{cm}$. As for the statistical analysis of the data for response 1, the cumulative pozzolan percentage predicted from the model was in agreement with the experimental values, with R-squared value of 0.9565 , which confirms the accuracy of the model. On the other hand, the $\mathrm{R}$-squared value for response 2 which is the EC decrement from 0 - 2 Minutes, it shows that the model was inline with the experimental values at 0.9342 . Thus, it justify the model precision.

\section{Acknowledgement}

The author would like to thank the Ministry of Education of Malaysia $(\mathrm{MoE})$ for funding the research work under MyRa Grant Scheme with cost centre 0153AB-J12. The author also wishes to extend her profound gratitute to all personnel in Civil Engineering Department of Technology PETRONAS University and International Islamic University Malaysia kind assistance in this research.

\section{References}

[1] Food and Agriculture Organization, Rice Market Monitor April 2016 (2016), available online: http://www.fao.org/fileadmin/templates/est/COMM_MARKETS_ MONITORING/Rice/Images/RMM/RMM_APR16.pdf, last visit: 15 July 2018.

${ }^{a}$ Significant under $95 \%$ level of confidence.

${ }^{b}$ Not significant relative to the pure error due to noise.

The interactions between $\mathrm{HCl}$ concentration, soaking time, burning temperature and soaking temperature are depicted in the three dimensional (3D) response surface plot shown in Fig. 1. As for Fig.1, interaction between soaking time and $\mathrm{HCl}$ concentration at constant soaking temperature and burning temperature of $80^{\circ} \mathrm{C}$ and $600^{\circ} \mathrm{C}$ was presented correspondingly. From the figure, it can be deduced that cumulative pozzolan percentage amount increases as soaking temperature increases. This phenomenon is due to the removal of metallic impurities that encapsulated on the surface of the rice husk during pretreatment process. Hence, it remarkably enhance the purity of UFTRHA produced via low concentration acid pretreatment process prior to burning process [4], [8], [9].[17].

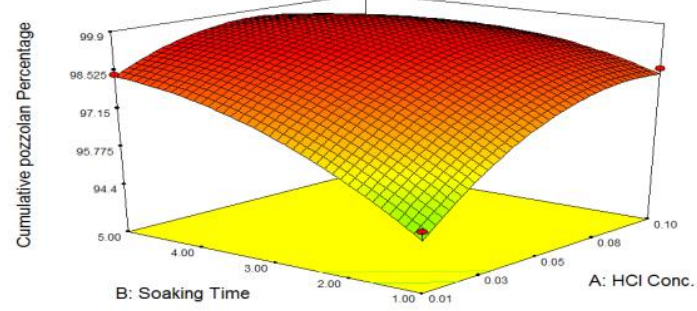

Fig.1: Response surface plot of cumulative pozzolan percentage: Effect of soaking time and $\mathrm{HCl}$ concentration at burning temperature and soaking temperature of $600 \mathrm{oC}$ and $80 \mathrm{oC}$ respectively.

[2] Kingsley KL (2010), Synthesis of High Purity Silicon from Rice Husks, University of Toronto.

[3] Bazarghan A, Bazargan M. \& McKay G (2015), Optimization of rice husk pretreatment for energy production, Renew. Energy, vol. 77, pp. 512-520.

[4] Feng Q, Yamamichi H, Shoya M \& Sugita S (2004), Study on the pozzolanic properties of rice husk ash by hydrochloric acid pretreatment, Cem. Concr. Res., vol. 34, no. 3, pp. 521-526.

[5] Park C, Salas A, Chung CW, \& Lee CJ (2014), Freeze-thaw resistance of concrete using acid-leached rice husk ash, KSCE J. Civ. Eng., vol. 18, no. 4, pp. 1133-1139.

[6] Salas A, Delvastro S, Gutierrez RMD, \& Lange D (2009), Comparison of two processes for treating rice husk ash for use in high performance concrete, Cem. Concr. Res., vol. 39, no. 9, pp. 773-778.

[7] Park K, Kwon S \& Wang X (2016), Analysis of the effects of rice husk ash on the hydration of cementitious materials, Constr. Build. Mater. Build. Mater., vol. 105, pp. 196-205.

[8] Vayghan AG, Khaloo AR \& Rajibipour F (2013), The effect of a hydrochloric acid pre-treatment on the physicochemical properties and pozzolanic performance of rice husk ash," Cem. Concr. Compos., vol. 39, pp. 131-140.

[9] Sankar S, Sharma SK, Kaur N, Lee B, Young D, Lee S \& Jung H (2016), Biogenerated silica nanoparticles synthesized from sticky, red, and brown rice husk ashes by a chemical method, Ceram. Int., vol. 42 , pp. $1-11$.

[10] Luxan MP, Madruga F, \& Saavedra J (1989), Rapid Evaluation Of Pozzolanic Activity Of Natural Products, Cem. Concr. Res., vol. 19, pp. 63-68. 
[11] McCarter WJ \& Tran D (1996), Monitoring pozzolanic activity by direct activation with calcium hydroxide, Constr. Build. Mater., vol. 10 , no. 3, pp. 179-184

[12] Mertens G, Snellings R, Van Balen K, Bicer-Simsir B, Verlooy P, \& Elsen J (2009), Pozzolanic reactions of common natural zeolites with lime and parameters affecting their reactivity, Cem. Concr. Res., vol. 39, no. 3, pp. 233-240.

[13] Villar-Cocina E, Morales EV, Santos SF, Savastano H, and Frias M (2011), Pozzolanic behavior of bamboo leaf ash: Characterization and determination of the kinetic parameters, Cem. Concr. Compos., vol. 33, no. 1, pp. 68-73.

[14] Alyamac KE, Ghafari E \& Ince R (2017), Development of ecoefficient self-compacting concrete with waste marble powder using the response surface method, J. Clean. Prod., vol. 144, pp. 192-202.

[15] Myers RH, Montgomery DC \& Anderson-Cook CM (2016) Response Surface Methodology: Process and Product Optimization Using Designed Experiments, $4^{\text {th }}$ edition, John Wiley \& Sons, New Jersey, pp.325-357.

[16] ASTM (2015), ASTM C618-15 Standard specification for coal fly ash and raw or calcined natural pozzolan for use in concrete, ASTM International, West Conshohocken, PA.

[17] Ugheoke IB \& Mamat O (2012), A critical assessment and new research directions of rice husk silica processing methods and properties, Maejo Int. J. Sci. Technol., vol. 6, no. 3, pp. 430-448. 